\title{
Novas Técnicas do Orçamento Público
}

\author{
Sebastião de Sant'Anna e Silva \\ Professor universitário (Universidade \\ Federal do Rio de Janeiro)
}

A teoria das finanças públicas e da política orçamentária e fiscal, assim como as técnicas de elaboração da programação financeira do Governo, tem sido objeto, nos últimos tempos, de uma significativa transformação. ${ }^{1}$

É verdade que a atividade financeira do Governo continua a ser considerada, de acordo com antiga tradição, como decorrente da existência de dois grupos de necessidades humanas: necessidades privadas, que podem ser satisfeitas através do sistema do mercado, e necessidades públicas, cujo atendimento exige a organização política da sociedade, ou seja a existência do Estado. Para a satisfação das necessidades privadas, produzem os indivíduos, as firmas e as empresas, bens privados (inclusive serviços), postos à venda no mercado, cujo preço depende essencialmente, embora não exclusivamente, de sua procura e oferta. Para a satisfação das necessidades públicas produz o Governo bens públicos (quase sempre sob a forma de serviços e só excepcionalmente de mercadorias), que não podem ser colocados à venda no mercado e cujos preços não podem ser fixados com base em sua procura e oferta. Diferenciação fundamental entre bens privados e públicos, é que o uso dos primeiros, os bens privados, está sujeito à cláusula de exclusão, só sendo admitidos a seu uso os indivíduos que disponham de poder de compra suficiente para adquiri-los pelos preços correntes no mercado. No caso dos bens públicos, não é

1 O Instituto Internacional de Finanças Públicas, em seu Congresso de 1971, em Nuremberg, sob o tema "Novos métodos de escolhas orçamentárias", realizou uma análise penetranté das novas técnicas e politicas relacionadas com o Orçamento Público. Os anais do Congresso foram publicados em 1972 pelo Instituto. 
porém admissível essa cláusula de exclusão, sendo todos os indivíduos integrantes de uma Nação admitidos à sua utilização, quer disponham ou não do poder de compra correspondente. Um indivíduo pode ficar privado do atendimento de necessidades privadas mais elementares, tais como as de alimentação e vestuário, se não dispuser de poder de compra para adquirir no mercado os produtos capazes de satisfazê-las. Ninguém, todavia, seja qual for o seu poder de compra, deixará de ter satisfeita, como integrante de uma comunidade política, sua parcela de necessidade de defesa ou de segurança.

Admite-se, porém, na moderna teoria das finanças públicas, a existência de um terceiro grupo de necessidades, denominadas por Richard P. Musgrave 2 de necessidades meritórias (merit wants). Trata-se de necessidades que, embora em princípio possam ser satisfeitas através do sistema do mercado, ou seja de forma idêntica às necessidades privadas, são consideradas de tão elevado mérito social, que se considera impossível sujeitar sua satisfação ao princípio da exclusão. Assim sendo, o Estado assume a responsabilidade total ou parcial pela satisfação de tais necessidades, através do suprimento de bens meritórios (merit goods) para sua satisfação. A saúde, certos níveis de ensino, o transporte das pessoas etc., são exemplos típicos de necessidades meritórias. É inegável que elas podem, em princípio, ser satisfeitas pelo sistema do mercado, através de empresas de educação, de saúde, de construção e de exploração de estradas, que venderiam aos usuários os serviços por elas produzidos. Como, todavia, o suprimento de tais serviços pelo sistema do mercado obedeceria ao princípio da exclusão e o Estado considera que ninguém deva ser excluído da satisfação de tais necessidades, assume o Governo a responsabilidade pelo seu suprimento. Ás vezes o suprimento de bens meritórios pelo Estado é inteiramente gratuito, como acontece com o ensino público primário. Outras vezes é cobrado por esse suprimento um preço político, que nada tem a ver com a sua oferta e procura (emolumentos cobrados nas Universidades). Algumas vezes o Estado faz o suprimento de tais serviços a toda a população. Outras vezes, limita esse suprimento a indivíduos cujo poder de compra é considerado insuficiente. Finalmente, pode acontecer que o Estado monopolize o suprimento sabilize apenas em parte por esse suprimento, ficando a parte

2 Richard P. Musgrave, The Theory of Public Finance, New York, 1959. 
restante a cargo das firmas e empresas privadas através do sistema do mercado.

Podemos, portanto, considerar a Administração Pública como uma enorme e complexa Empresa, ou um conglomerado de empresas produtoras de uma variada gama de serviços que devem atender a necessidades coletivas, públicas e meritórias. A organização administrativa pode, portanto, ser equiparada a um sistema de produção, com estrutura correspondente à organização hierárquica e territorial dos serviços públicos. Os bens gerados por esse sistema de produção não são vendidos ao público através do mercado, mas lhe são fornecidos gratuitamente ou mediante um preço político, sendo sua produção financiada por transferências compulsórias de renda. Os fatores utilizados para operar esse sistema de produção são adquiridos no mercado, salvo casos excepcionais nos quais ainda se utiliza o processo de requisição (serviço militar, eleitoral, do júri). o problema gerencial mais importante na esfera da Administração Pública consiste, portanto, em estabelecer métodos e sistemas através dos quais se torne possível conseguir que os fatores de produção adquiridos pela Administração sejam efetiva, econômica e eficientemente utilizados na produção dos serviços sob sua responsabilidade.

A orçamentação é tradicionalmente considerada, tanto na Administração Pública como na Administração Privada, como técnica adequada para programar a produção e o suprimento de bens durante um determinado período de tempo, assim como a alocação eficiente de fatores para a produção desses bens. $O$ que distingue a técnica da orçamentação pública da orçamentação privada é o fato de que, na primeira, trata-se de programar a produção e o suprimento de bens cujo volume e qualidade não são determinados pelo mercado, mas por decisões de natureza política. É necessário, portanto, na orçamentação pública, encontrar técnicas diferentes e mesmo mais sofisticadas do que as utilizadas na orçamentação privada, para conseguir, também na primeira, uma alocação racional, econômica e eficiente de recursos. O problema torna-se ainda mais importante, uma Vez que a Administração Pública disputa com a Administração Privada os fatores escassos disponiveis e tem a possibilidade de efetuar em seu favor, transferências compulsórias desses fatores. Torna-se, portanto, imprescindivel encontrar métodos e técnicas capazes de orientar o uso alternativo desses fatores dentro da própria Administração Pública e entre esta e a Admi- 
nistração Privada. As novas técnicas orçamentárias, algumas das quais vamos analisar neste trabalho, visam um objetivo de eficiência nos gastos públicos ou no uso pelo Governo de fatores escassos, para produzir, pelos menores custos possiveis, bens públicos e meritórios, capazes de proporcionar 0 máximo de bem-estar com o mínimo sacrifício coletivo.

O que caracterizava a técnica orçamentária tradicional era, em primeiro lugar, a preparação de estimativas de despesa partindo das unidades administrativas, que eram convocadas a formular suas necessidades de recursos financeiros para a execução de seus programas específicos. Esses programas, limitados ao período de um ano, eram apresentados sob a forma de uma relação de gastos (despesas com pessoal, material, serviços, obras etc.) e não dos resultados que se pretendia al-
cançar. ${ }^{3}$

A fase inicial de um moderno sistema orçamentário consiste em uma avaliação das necessidades públicas e das necessidades meritórias que o Estado se dispõe a atender durante o período de tempo abrangido pelo plano ou programa do governo no poder. Essa avaliação é em primeiro lugar qualitativa e em seguida quantitativa. A avaliação qualitativa consiste em relacionar as necessidades a serem atendidas e é, antes de tudo, um problema político, notadamente no que diz respeito às necessidades meritórias. A filosofia política dominante, 0 programa do partido ou grupo que detém o poder, a força dos diversos grupos de pressão etc., ditam o grau de intervenção social do Estado e que necessidades são consideradas meritórias para determinar o seu atendimento total ou parcial pelo Governo. Inclui-se ainda na avaliação qualitativa das necessidades públicas e meritórias o estabelecimento de escalas de prioridade para sua satisfação. As avaliações qualitativa e qunatitativa então se interpenetram e se confundem. A satisfação de necessidades, sejam elas privadas, públicas ou meritórias, é um problema econômico. Trata-se, na verdade, da alocação de recursos limitados, para atender a um rol praticamente ilimitado de necessidades. Face à impossibilidade de se satisfazer a todas elas, cumpre o estabelecimento de hierarquias e escalas

3 No Governo Castelo Branco modificou-se a técnica da elaboraçăo orcamentária de baixo para cima: apresentação das estimativas a técnica da elaboraçăo orçamentária de baixo paraçăo da proposta orçamentária por ministérpesa pelas unidades administrativas, prepartir de 1964 passou-se para a por ministérios e aprovaçăo final pelo Presidente. A do programa orçamentário global elaboraçăo orçamentária de eima para baixo: definiçăo prioridades, estabelecimento global em reuniăo do Ministério para o estabelecimento de determinaçắo de quotas de do teto da despesa geral, fixaçăo do deflcit admissivel R. Serv. Públ., Brasiltia 
de prioridade para sua satisfação. As consideradas como prioritárias obterão satisfação integral, as menos urgentes satisfação parcial e as adiáveis terão sua satisfação transferida para 0 futuro.

A técnica orçamentária acima sintetizada constitui o chamado "orçamento programa", pois sua base está no plano ou programa plurianual do Governo e nas metas e prioridades nele estabelecidas. A elaboração das estimativas pelas unidades administrativas não é mais o núcleo do processo orçamentário e sim uma fase secundária e dependente, pois os programas dessas unidades constituem apenas subprogramas, cujos limites, objetivos e importância dependem das metas e objetivos fixados no plano ou programa global. Essa nova técnica passou a exigir, inclusive, a modificação da forma de apresentação do documento orçamentário, a ser baseado em uma classificação funcional, na qual as autorizações de despesa são grupadas de acordo com seus objetivos (defesa nacional, educação, recursos naturais etc.), independentemente das unidades administrativas ou departamentos responsáveis pelos gastos.

Essa transformação da técnica orçamentária é que originou a transferência, efetuada pela Reforma Administrativa, do DASP para o Ministério do Planejamento, da responsabilidade pela elaboração da Proposta do Orçamento Geral da União. Quando realizou, nas décadas de 30 e 40 , o magnífico e patriótico trabalho de reorganizar a Administração Federal, por ordem no serviço público, selecionar e profissionalizar o servidor civil, racionalizar e dar eficiência à máquina administrativa, necessitou - DASP de comandar a elaboração orçamentária como instrumento imprescindível para a execução desse trabalho disciplinador. A técnica orçamentária consistia então, principalmente, em conseguir, no contato direto com as unidades administratiVas, boas estimativas orçamentárias capazes de dotá-las de recursos adequados a um trabalho eficiente. Todavia, quando a partir de 1964 surgiu a imperiosa necessidade de um planejamento econômico a longo prazo, para conter a inflação que paralisara o crescimento econômico do país e assegurar a retomada e aceleração desse crescimento, tornou-se imperioso transformar o orçamento em instrumento desse planejamento econômico e atribuir a responsabilidade pela sua elaboração ao órgão responsável pela preparação do plano econômico do Governo e coordenação de sua execução. 
Para que o Orçamento Público seja um instrumento efetivo para a programação, a longo prazo, das atividades do Governo, preocupam-se os economistas e financistas em encontrar métodos e sistemas para a fixação de escalas de prioridade na satisfação das necessidades públicas e meritórias. O sistema PPBS (Planning, Programming, Budgeting System) e a análise do "Custo/Benefício" constituíram, sem dúvida, um grande progresso no sentido da consecução de critérios objetivos, capazes de nortear os elaboradores do orçamento público na tomada de decisões, fixação de hierarquias e prioridades e na avaliação dos resultados da execução de programas governamentais. O PPBS é, na sua essência, um processo de elaboração orçamentária que procura especificar programas e objetivos em termos quantitativos, medir benefícios e procurar soluções a custos mais reduzidos. Deve-se, porém, estar sempre atento para o fato de que a Administração Pública nunca pode ser inteiramente equiparada às empresas privadas, que serviram de modelo para a introdução da técnica do PPBS. ${ }^{4}$ Nas empresas privadas qualquer orientação estabelecida ou decisão tomada deverá ter sempre em vista a consecução de um lucro nas operações a serem realizadas. Esse lucro será sempre a resultante de um benefício superior ao custo, ambos perfeitamente mensuráveis em dinheiro. Na Administração Pública, embora o custo seja sempre suscetível de apuração em termos quantitativos, o benefício, freqüentemente, não é suscetivel de tal apuração, dado o seu rável o custo monetário de um programa de defesa nacional, torna-se impossivel quantificar os benefícios dele resultantes do prestígio nacional etc.). Em conclusão, as decisões em marazões e considerações de natureza política e não baseadas em motivos de ordem estritamente econômica. Além de ser um sistema cuja finalidade principal é possi-
bilitar a tomada de decisões racionais em matéria orçamentá-
ria, o PPBS é um método pesalo ria, o PPBS é um método pelo qual se procura definir os obje-

\footnotetext{
4 Em 1967, tivemos a oportunidade de participar, Juntamente com oflcials superlores das de Pittsburgh, promovido e de diversos outros palses, de um com oflcials superlores das mentos da Defesa Nacional". Departamento de Defesa dos Im Seminário na Universidade inaugurada, nos Estados Unidos, nos explicado, na ocasiăo, que a técnica do PPBS fora Secreo de Secretário da Des, no Departamento da Defesa, quando Mc Namara assumiu de oretário, impressionado com a inexindo da presidência da Ford Motor Co., o novo ao então versos outrosta na Ford. O sistema de custos, introduziu ali um sistema semeihante departamentos da Administraçăo Federal Americana.
} 
tivos a longo prazo (plano) de uma determinada atividade governamental, delinear as diversas alternativas possíveis (programa de ação) para atingir esses objetivos, assim como identificar quais os recursos necessários para execução de cada uma dessas alternativas (orçamentação). $\mathrm{Na}$ definição de um especialista, "A análise sistemática dos caminhos alternativos para alcançar objetivos é o coração e a alma do PPBS na elaboração orçamentária". 5 Podemos enumerar como as seguintes as características do PPBS:

a) orientação baseada na produção e não nos gastos do serviço considerado;

b) planejamento e programação para vários anos;

c) uso de instrumentos de análise (análise do custo/benefício) para o exame, não só dos objetivos, como também dos diversos programas alternativos para atingi-los.

A primeira fase do sistema PPBS situa-se, portanto, no planejamento a longo prazo das atividades governamentais. Nessa fase inicial tem lugar a elaboração e a aprovação do plano global do Governo, no qual suas diretrizes são definidas, são fixados os objetivos (metas) a atingir e estabelecidas as hierarquias $e$ as escalas de prioridade entre esses objetivos.

A segunda fase exige o detalhamento do plano global do Governo nos diversos programas a serem elaborados e exeCutados para a consecução dos objetivos estabelecidos. É nesta segunda fase que se torna importante a utilização de instrumentos, tais como a análise do custo/benefício, que permite estabelecer comparações entre os custos e os resultados de programas alternativos de ação. Citamos abaixo as caracterís. ticas que nos pareceram as mais importantes da análise custo/ benefício, na relação apresentada por um especialista, em um manual clássico sobre a matéria. ${ }^{6}$

1.9) O exame sistemático e a comparação entre formas alternativas de ação que podem ser adotadas para alcançar objetivos específicos em um determinado período de tempo.

5 A.M. Rivlin - "The Planning. Programming and Budgetary System in the Department of

Health, Education and Welfare". Joint Economic Committee, Washington, D.C., 1969.

6 Gene H. Fischer, The Role of Cost - Utility Analysis in Program Budgeting, in "Mannual for Programme and Performance Budgeting, New York, 1965. 
2.) Uma análise crítica de alternativas envolvendo numerosas considerações, sendo as duas principais: a) a avaliação dos custos (no sentido de custo de recursos econômicos) e b) a utilidade (ganhos e benefícios) decorrentes de cada uma das alternativas.

3. ) O tempo a se considerar, ou seja o futuro, às vezes um futuro distante: cinco anos, dez anos ou mais.

4..$\left.^{\circ}\right)$ Um ambiente de incerteza, às vezes mesmo de grande incerteza, devido ao longo período de tempo visualizado, incerteza esta porém que, pelo fato de ser um fator importante, deverá ser encarada de frente e explicitamente tratada na análise.

5. $\left.{ }^{2}\right)$ Tema amplo e ambiente muito complexo em torno do qual a análise se realiza, o que dá lugar a várias interações entre as variáveis-chave do problema, significando que as soluções simples e diretas constituem a exceção e não a regra.

6. $\left.{ }^{\circledR}\right)$ Uso ao máximo possível de métodos quantitativos de análise, devendo esse trabalho puramente quantitativo, sempre que necessário, ser suplementado por uma análise qualitativa.

Cumpre, todavia, salientar que a análise custo/benefício não é às vezes suficiente, por si só, para levar a uma solução, ou seja a uma decisão sobre a adoção de determinada política ou de determinado curso de ação. A finalidade da análise custo/ benefício é a de qualquer outro método orçamentário: conseguir o máximo de eficiência nos gastos do Governo, da mesma forma que o indivíduo ou a empresa privada procura, também, o máximo de eficiência (resultados) em seus dispêndios. Ora, uma despesa, tenha ela lugar no setor público ou no setor privado, só pode ser considerada eficiente: a) quando os benefícios dela decorrentes têm uma relação com os custos correspondentes de outras despesas com ela comparáveis; e b) quando se verifica que o objetivo por ela visado não poderia ser alcançado com um dispêndio menor. Por exemplo, poderemos dizer que o custo de uma maternidade de 200 leitos mantida pelo Governo é eficiente: a) se esse custo é comparável com o de outras maternidades públicas ou privadas da mesma dimensão e do mesmo nível de tratamento; b) se for verificado que não é possível manter idêntico número de leitos e o mesmo nível de tratamento por um custo menor. 
Antes de concluirmos o presente trabalho, não será demais salientar que o sistema PPBS e a análise custo/benefício não são instituições genuinamente capitalistas, modeladas exclusivamente na administração de empresas privadas, onde o objetivo do lucro elimina quaisquer outras considerações, nem aceitar a opinião de que tais métodos não são adequados à Administração Pública, onde os objetivos a considerar são de caráter exclusivamente político-social. Ao contrário, o PPBS e a análise custo/benefício são instrumentos neutros de trabatho, assim como as técnicas do planejamento e da programação e, como tais, utilizáveis em um Estado como o brasileiro, que faz repousar na iniciativa e na propriedade privadas o seu sistema econômico, como também em um Estado cuja economia se movimenta na base do dirigismo total e da propriedade coletiva dos meios e instrumentos de produção.

O que se torna necessário é reconhecer a limitação de tais métodos e a necessidade de sua complementação, como o faz de forma decisiva um dos mais conhecidos e reputados autores da moderna teoria das Finanças Públicas e da Política Fiscal:

"Técnicas como as do PPBS e CB (análise do custo/benefício) são úteis ao desvendar as conseqüências das escolhas governamentais, mas não oferecem razões para remover essas escolhas da arena política. De fato, a melhor estratégia para os devotos do PPBS é fazer com que os políticos entendam inteiramente seus usos e limitaçōes, como, por exemplo, através de modificações adequadas dos processos para o exercício do controle político das despesas públicas. A melhoria das informações fornecidas à Administração Governamental pelas novas técnicas pode revelar tipos de comportamento, por parte de servidores públicos, inadequados à consecução de eficiência, mas essas técnicas, por si só, nada podem fazer diretamente para a modificáção desse comportamento. Os que acreditam no sistema do mercado como força disciplinadora desejam ver essas técnicas suplementadas por métodos capazes de estimular o mercado de trabalho para o serviço público." 7

\footnotetext{
7

Alan T. Peacock, New Methods of Appraising Government Expenditure: An Economic

Analysis - York - U.K., 1971.
} 
O DASP se inscreveu na história administrativa do Brasil como inovador e introdutor de novas técnicas e novos métodos para a melhoria da eficiência e dos resultados do serviço público. Dentre as suas grandes realizações, creio que se inscreve, em primeiro lugar, a profissionalização do serviço público, a seleção e o recrutamento de valores para o serviço do Estado e a conservação desses valores no serviço do Governo, através de remuneração adequada e estímulos idênticos aos que prevalecem em um mercado de trabalho em permanente desenvolvimento, como é o nosso. Só uma política de pessoal assim orientada, pode garantir que métodos e sistemas modernos de administração, como o PPBS, a análise custo/benefício e outros, cuja implantação e execução exigem técnicas, técnicos $e$ instrumental especializados, possam ser utilizados na fase, ora atravessada, de expansão acelerada de nossas potencialidades econômicas e sociais, sob o controle, orientação e estímulo governamentais. 